\title{
Understanding Attitudes to Change to Healthier Hydration Habits: The Case of High Sugar: Low Water Drinkers in Mexico
}

\author{
Julie Mayer ${ }^{a}$ Aukje Anna Catharina Verhoeven ${ }^{b}$ Quentin Dornic ${ }^{c}$ \\ Houda Hanzouli $^{d}$ Isabelle Seksek ${ }^{e}$ Isabelle Guelinckx ${ }^{e}$ Homero Martinez ${ }^{f}$

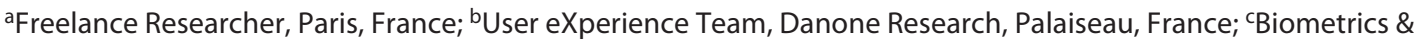 \\ Data Science Department, Danone Research, Palaiseau, France; dSolution BI, Paris, France; 'Department of Health, \\ Hydration \& Nutrition Science, Danone Research, Palaiseau, France; ${ }^{f}$ Hospital Infantil de México Federico Gómez, \\ Mexico City, Mexico
}

\section{Keywords}

Sugar-sweetened beverages - Water - Attitudes - Behavior · Hydration · Mexico

\begin{abstract}
Adults consuming sugar-sweetened beverages (SSBs) are at increased risk of becoming overweight/obese and developing lifestyle-related diseases. Furthermore, a low water intake is associated with increased health risks, such as CKD. These issues are especially pressing in Mexico where SSB intake is high. The present research aimed to describe the attitudes of Mexican adults who are considered high sugarlow water drinkers (HS-LWDs). HS-LWDs were defined as adults aged $18-45$ years, drinking at least 2 servings $(500 \mathrm{~mL})$ of SSB/day and maximum 3 servings $(750 \mathrm{~mL})$ of water/day. The study included 2.858 HS-LWD (58\% males) living in the urban area of Mexico City. Data were collected using an online, self-administered questionnaire. Bayesian approach was applied to analyze attitudes in life and towards drinking. Results showed that social aspects, such as sharing with friends and family and self-image, were the dominant attitudes in life. The main reason to choose a beverage was to
\end{abstract}

karger@karger.com www.karger.com/anm

Karger $\frac{1}{\%}$

GOPEN ACCESS
(C) 2021 The Author(s)

Published by S. Karger AG, Basel

This article is licensed under the Creative Commons AttributionNonCommercial-NoDerivatives 4.0 International License (CC BYNC-ND) (http://www.karger.com/Services/OpenAccessLicense) Usage and distribution for commercial purposes as well as any distribution of modified material requires written permission. get sensations, resulting in 2 axes, one was pleasure oriented and one was health oriented. Getting sensations was also a main driver to drink linked to a moment, together with selfimage. The Bayesian network analysis demonstrated 5 attitude profiles, based on the most important attitudes defining each profile: mood and pleasure, self-image and body image, sharing and restoring, pleasure and energy, and health and success. This study allowed describing HS-LWD attitudes, in life and towards drinking. It constitutes a first step in understanding this target group's attitudes and behavior, offering potential recommendations for tailored interventions to promote the adoption of healthier drinking habits.

(c) 2021 The Author(s)

Published by S. Karger AG, Basel

\section{Introduction}

Convincing evidence shows that regular consumption of sugar-sweetened beverages (SSBs) increases the risk of becoming overweight or obese $[1,2]$ and developing type2 diabetes $[3,4]$. Moreover, low water intake is associated with health risks such as CKD [5], whereas optimal water 
intake positively impacts various aspects of health [6]. Therefore, bodies, such as the World Health Organization, urge actions to promote healthier drinking behavior [7].

One country that stands out in terms of SSB intake is Mexico [8]. Here, SSB is the main source of added sugar intake [9]. It is estimated that the median intake of SSB among Mexican adults is $531 \mathrm{~mL} /$ day with P75 reaching up to $895 \mathrm{~mL} /$ day [10]. Furthermore, $37 \%$ of the Mexican adults consume $\geq 2$ servings of SSB and $\leq 3$ servings of water per day (unpublished data, Liq. $\operatorname{In}^{7}$ survey [10]). Overweight and obesity prevalence affects over $60 \%$ of adults [11], and diabetes prevalence increased from 7\% in 2006 to $9.4 \%$ in 2016 [12]. Non-communicable diseases and excess mortality can be directly related to SSB consumption in Mexico [13]. Hence, reducing SSB consumption and increasing healthier beverages intake is crucial.

Although specific fluid intake patterns, such as high SSB and low water intake, have been associated with sociodemographic and health-related determinants [14], little is known about the link with psychosocial aspects. According to socioecological models, psychosocial factors are important in shaping health behaviors, interacting with social, economic, physical, and biological factors [15]. More specifically, researchers have emphasized the predictive role of attitudes when explaining and changing behavior [16, 17], including SSB consumption [18-20]. Therefore, understanding attitudes appears as a first step to help people adopt healthier drinking habits through behavior change strategies.

\section{Aim of the Study}

This study aimed to describe high sugar-low water drinkers (HS-LWDs) beverage consumption and attitudes, toward life and drinking non-alcoholic beverages, in Mexico, to identify potential drivers of behavior that could be used to promote healthier drinking habits.

\section{Methods}

A cross-sectional survey was conducted among HS-LWD aged 18-45 years, living in the Metropolitan area of Mexico City (Greater Mexico City). Data were collected in December 2017 and January 2018, excluding Christmas holidays.

\section{Sample}

Inclusion criteria

Age 18-45 years; literacy; online access; HS-LW drinking status based on the Fluid intake assessment: average daily consumption $\geq 500 \mathrm{~mL} \mathrm{SSB}$, corresponding to $\geq 45$ g liquid sugar $(9 \mathrm{~g} / 100 \mathrm{~mL}$, based on the average liquid sugar content for the top 3 beverage categories in Mexico: sugar-sweetened sodas, juices and fruits nectars, still flavored water); and $\leq 750 \mathrm{~mL}$ plain water; non-participation in market research within the past 6 months; not having oneself or family in marketing, advertising, beverage manufacturing and media industry; living in Greater Mexico City; not pregnant; and no binding medical treatment or diet.

\section{Recruitment}

Via online panels, with quotas for sex (50\% male) and age (equal distribution of 18-25 years, 26-35 years, and 36-45 years), slight deviations were allowed. The final sample included 2.858 participants (see Fig. 1 for Flow chart). All participants gave written approval. Non-monetary incentives like iTunes points were offered after questionnaire completion. Data were recorded and analyzed anonymously.

\section{Materials}

Fluid Intake Assessment

Participants indicated the types of beverages they consumed on a typical weekday and the amount (in number of cups of $250 \mathrm{~mL}$ ). Beverage categories based on the Liq. In $^{7}$ diary [10] included (in randomized order): plain water (tap/bottled, still/sparking), fruit juice and nectar, soda (sugar-sweetened), still flavored water, sparkling flavored water, ready to drink tea, homemade fruit juice, light and sugar-free soda, homemade flavored water, flavored water made from powder/concentrated/syrup, flavored milk bottled, sport and energy drink, hot coffee and tea, and others.

\section{Demographic Variables}

Height and weight were self-reported. BMI was calculated as $\mathrm{kg} / \mathrm{m}^{2}$ and classified as underweight $\left(<18 \mathrm{~kg} / \mathrm{m}^{2}\right)$, normal $(18-24.9$ $\left.\mathrm{kg} / \mathrm{m}^{2}\right)$, overweight $\left(>25 \mathrm{~kg} / \mathrm{m}^{2}\right)$, or obese $\left(>30 \mathrm{~kg} / \mathrm{m}^{2}\right)$. Education level and professional status were self-reported. Socioeconomic status was determined using a system based on selected characteristics of households (e.g., number of rooms in the home and access to gas and electricity), leading to a score (class A to class E, A being the highest) [21]. Participants self-reported their practice of sport in number of hours per week.

\section{Attitudes}

The overall questionnaire comprised 63 questions. Our analysis focused on the sets of questions concerning attitudes. A previous qualitative study was conducted among 24 Mexican adult HS-LWD to understand the attitudes in life and toward drinking to develop the present questionnaire. The following aspects were addressed:

- Attitudes in life (17 items, randomized, e.g., "being independent is an objective in my life," "my health is a priority"); 5 -point Likert scale ("fully agree"-"fully disagree").

- Control over food and drinks (3 items, single answer): "most of the time, I control/reduce my daily consumption of food and drinks," "most of the time, I consume the food and drinks I want without control or restriction," "depending on moments and mood, I control or not the food and drinks I consume."

- Personality profile: "out of the following qualifiers, which are the 3 that characterize you the best?" (18 items, randomized, e.g., "generous," select 3 items), followed by "now sort the remaining words in 2 piles: the ones that may apply to you and the ones that may not."
Mayer/Verhoeven/Dornic/Hanzouli/ Seksek/Guelinckx/Martinez 


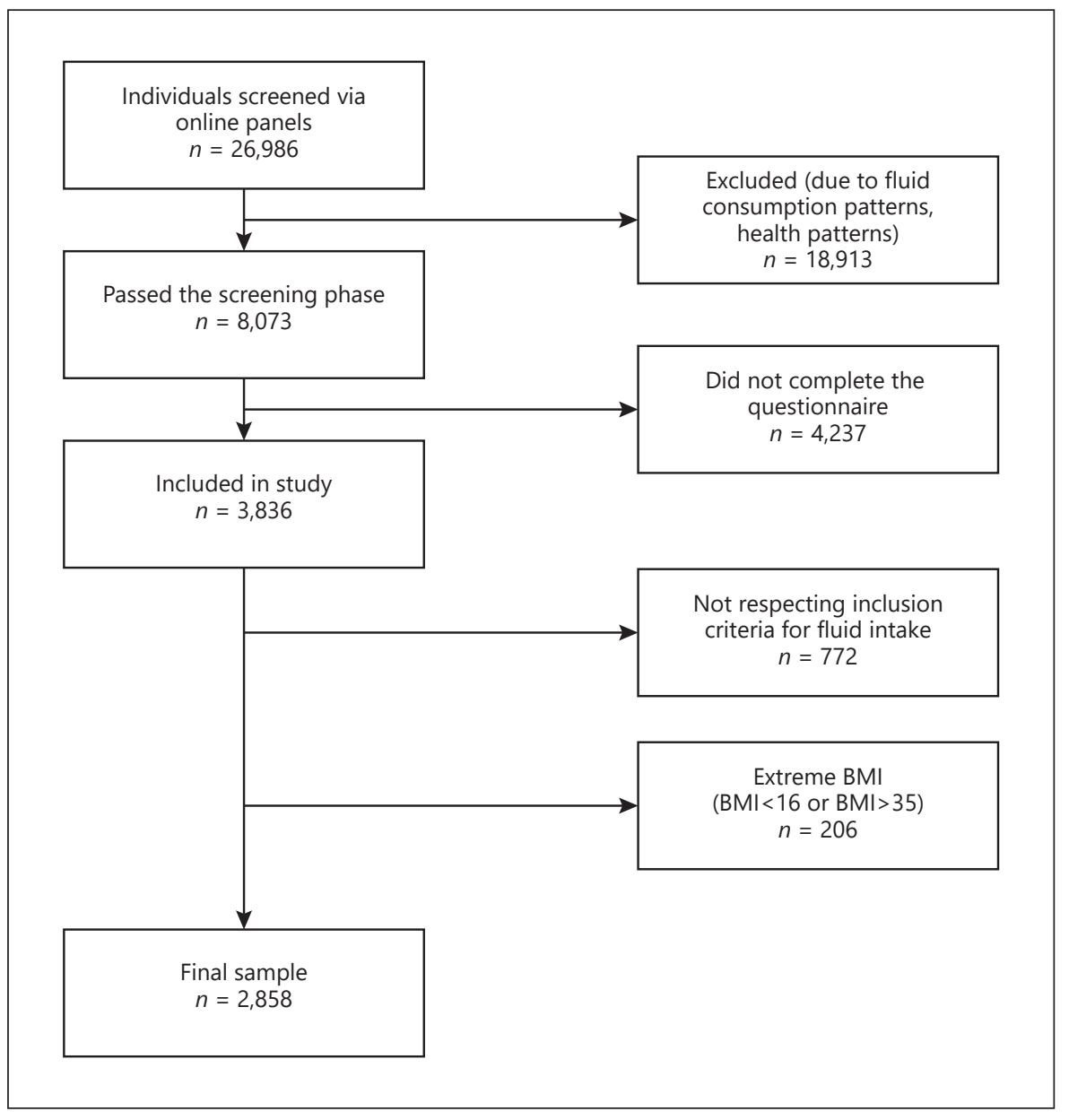

Fig. 1. Flow chart of sample selection.

- Representation of drinking non-alcoholic beverages (6 items, single answer): "drinking is a physiological need," "drinking is a way of taking care of me," "drinking is a pleasure," "drinking is a sharing moment, "drinking is a constraint," "nothing in particular."

- Impact on health per type of drink (randomized order), for plain water (tap/bottled, still/sparking), sodas, flavored water and fruit juice and nectar; 5-point Likertscale ("very impacting""not impacting at all").

- Reasons to drink non-alcoholic beverages (26 items, randomized, e.g., "restore energy"; 5-point Likert scale ("very often""never").

- Reasons to drink, linked to a brand (8 items, randomized, e.g., "I drink form a brand that I trust"; 5-point Likert scale ("very important"-"not important at all”).

- Reasons to drink, linked to moments: 20 items, randomized (e.g., "a natural drink"), to link with 7 reasons to drink (e.g., "cleaning my body," "sharing moments").

- Trendsetter index, 5 items, randomized (e.g., "I am often asked for advice about new food and drinks"); 5-point Likert scale ("fully agree"-"fully disagree").

Questionnaire is available upon request.

\section{Statistical Analysis}

Total fluid was calculated in means (standard deviations between brackets). Declared total fluid consumption above $8 \mathrm{~L} /$ day was considered missing due to low plausibility $(n=16)$. To understand what drives attitudes and to classify the studied population, a Bayesian network-based classification [22] was conducted. BayesiaLab-7.0.1 [23] was applied to describe the data dependencies and classify Mexican respondents according to their answers on attitudes. This Machine Learning tool included several supervised and non-supervised Bayes Learning versions. Here, the Markov augmented cover algorithm was applied.

\section{Results}

\section{Sample Description}

The sample included slightly more males (58\%). Participants aged 18-25 years and 26-35 years were equally represented (40\%), 20\% were 36-45 years. Forty-eight percent completed college degree or higher. Regarding socio-economic status, over $70 \%$ were class AB (29\%), C+ 


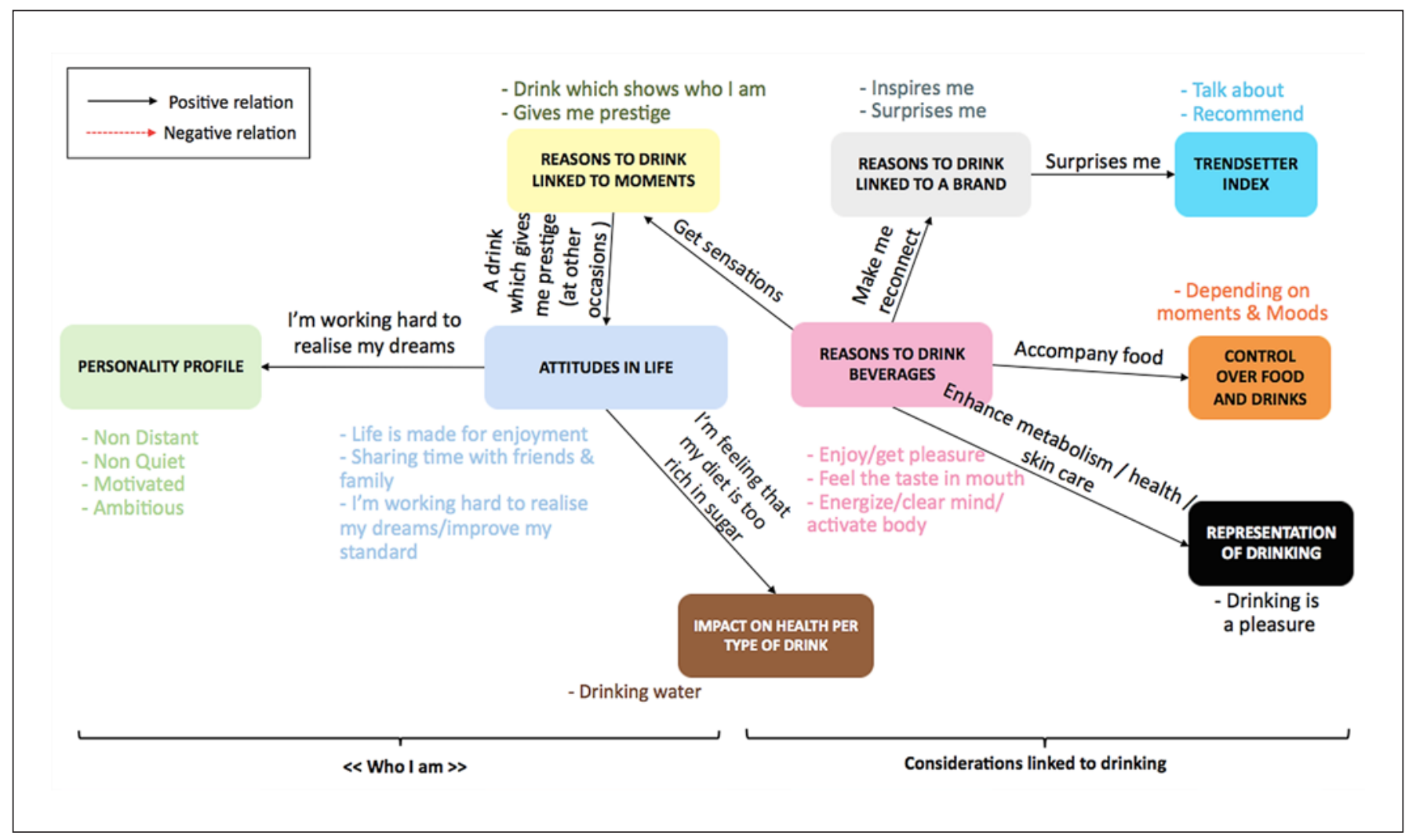

Fig. 2. Bayesian network analysis on attitudes. Main modalities structuring the answers (colored items), parent/ child relationships (arrows), and main items mediating the parent/child relationships between the 10 sets of questions on attitudes (items on arrows).

(29\%), and C (16\%). The majority (70\%) worked full time or part time. Mean BMI was $24.4 \mathrm{~kg} / \mathrm{m}^{2}\left(3.8 \mathrm{~kg} / \mathrm{m}^{2}\right)$, with $54 \%$ having a normal BMI, $32 \%$ overweight, and $8 \%$ obesity. Fifty-two percent practiced no sport or less than an hour/week.

\section{Beverage Consumption}

Mean total daily intake was $2.52 \mathrm{~L}(1.27 \mathrm{~L})$ of fluids/ day (water intake: $M=0.27 \mathrm{~L}, \mathrm{SD}=0.27 \mathrm{~L}$ ), corresponding to $123 \mathrm{~g}(70 \mathrm{~g})$ of liquid sugar and $492 \mathrm{kcal} /$ day, with $77 \%$ of participants consuming 3 or more servings of SSB $(\geq 750 \mathrm{~mL})$, and $23 \%$ between 2 and 3 servings of SSB $(\geq 500$ and $<750 \mathrm{~mL}$ ) daily.

\section{Bayesian Network Analysis on Attitudes}

The Bayesian network is summarized in Figure 2. "Reasons to drink beverages" and "attitudes in life" were the 2 central sets of questions (parent nodes) positively correlated with the other sets of questions (child nodes), suggesting that these aspects are the entry points for understanding HS-LWD attitudes. The relationship between "reasons to drink beverages" and "attitudes in life" was mediated by the "reasons to drink linked to moment," suggesting that reasons to drink beverages depend on the moment of consumption, which relates to their attitudes in life.

Figure 2 also presents the main items of each set of questions that mediates the relationship of the network. These items related mainly to sharing (with friends and family), enjoyment/pleasure, surprise, taste, functional benefits ("energize/clear mind"), self-image ("drink which shows who I am," "gives me prestige"), and achievement ("working hard to realize my dreams").

\section{Attitudes in Life}

Attitudes in life were structured around 2 dimensions: one on friends and family (e.g., "it is important to me to regularly share time with my friends and extended fami-
46

Ann Nutr Metab 2020;76(suppl 1):43-52 DOI: $10.1159 / 000515023$
Mayer/Verhoeven/Dornic/Hanzouli/ Seksek/Guelinckx/Martinez 


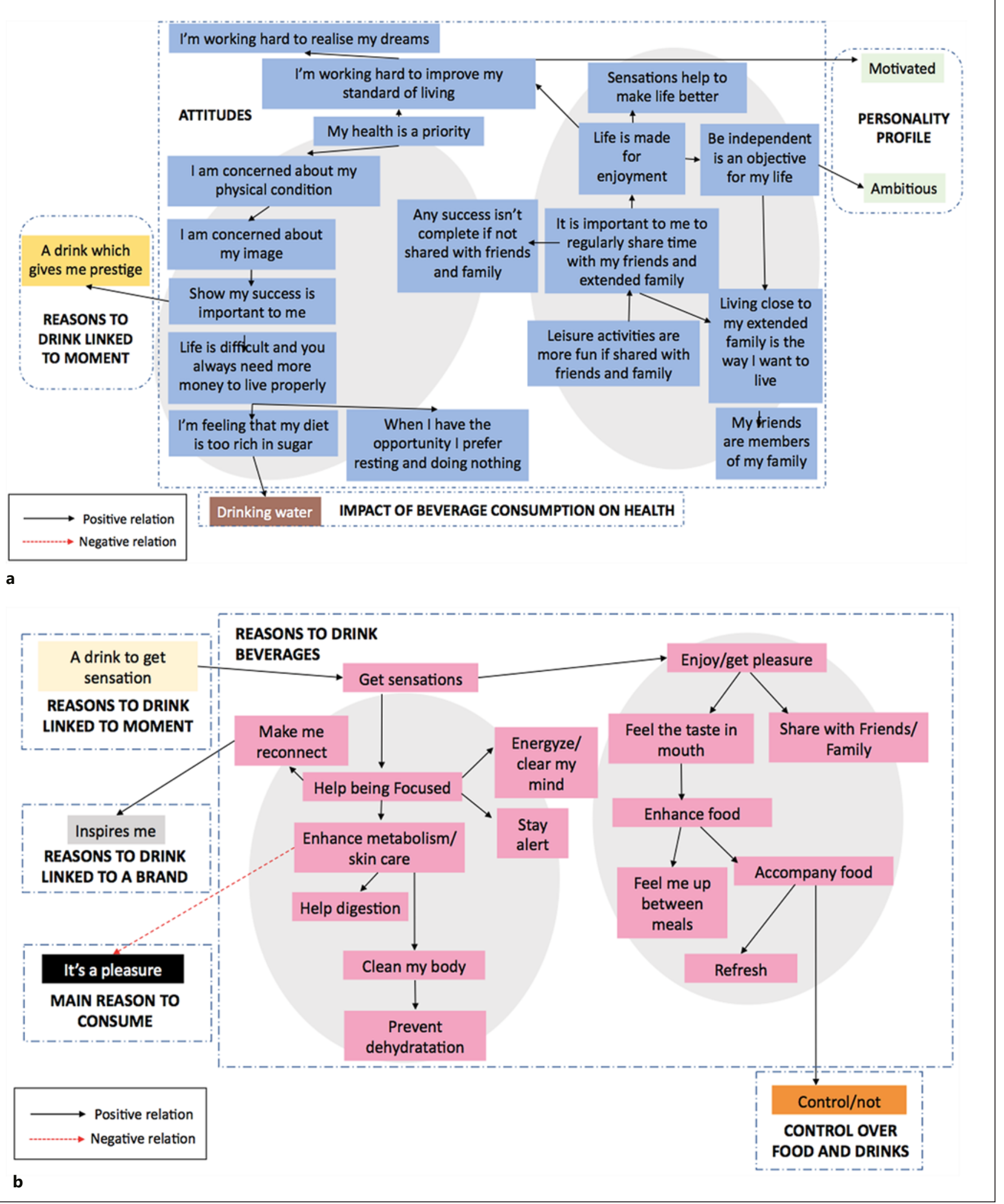

Fig. 3. Zoom-in on Bayesian network analysis on attitudes. Black line, positive relation; dotted red line, negative relation. a Attitudes in life. b Reasons to drink beverages. c Reasons to drink linked to moment. d Reasons to drink linked to a brand.

(Figure continued on next page.)

Understanding Attitudes to Change to Healthier Hydration Habits
Ann Nutr Metab 2020;76(suppl 1):43-52 DOI: $10.1159 / 000515023$ 


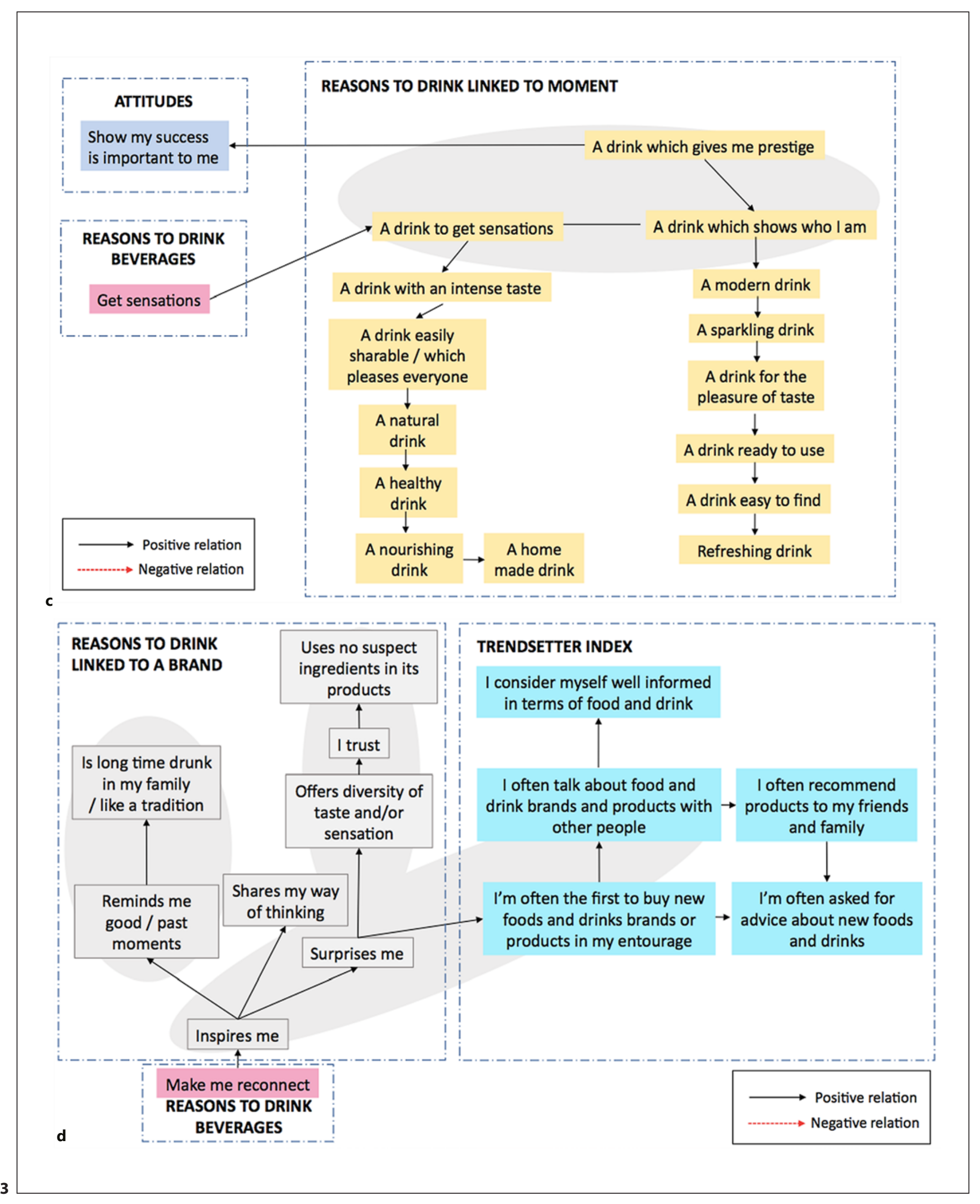


ly") and one on self-image ("I am concerned about my image") (Fig. 3a). The results suggest that social aspects are the dominant HS-LWD attitudes in life. Whereas the family-oriented dimension is not linked to specific beverages or moments, the self-image dimension is linked with a health preoccupation and is positively linked to the idea of drinking water for health purposes, mediated by a recognition that "...my diet is too rich in sugar."

\section{Reasons to Drink}

"Get sensations" was the main reason to drink beverages (Fig. 3b) and lead to 2 other reasons: one is for pleasure, taste, and related to the meal, the other one is health oriented, positively linked with benefits such as "enhance metabolism/skin care" and "clean my body." As with the attitudes in life, a dichotomy appeared between pleasure and health. This conclusion was also supported by the negative link between "enhance metabolism/skin care" and "it's a pleasure."

\section{Reasons to Drink Linked to Moments}

Reasons to drink linked to moments (Fig. 3c) were driven by sensations and by self-image. Getting sensations was positively associated with an intense taste, a beverage that is easily shareable and pleases everyone, a natural, healthy, nourishing, and homemade beverage. Self-image was positively associated with a modern and sparkling drink, for the pleasure of taste, ready to use, ready to find, and refreshing.

\section{Reasons to Drink Linked to Brands}

A main reason to drink linked to a brand was to get inspired, which was positively associated with items relating to one's past and cultural background ("reminds of good/past moments") and with "surprises me" (Fig. 3d). Being surprised was positively linked with items that define trendsetters (e.g., "I am often the first to buy new food and drinks brands or products in my entourage").

Overall, social aspects (sharing with family, friends and self-image) were the dominant HS-LWD attitudes in life. The main reason to choose a beverage was to get sensations, leading to 2 axes. The first one was pleasure oriented, also referring to potential social aspects (sharing time with friends and family and accompany food). The second driver was health oriented, referring to a list of individual benefits (e.g., "help being focused," "cleaning my body"). Getting sensations was also a main driver to drink linked to a moment, together with self-image ("a drink which shows who I am," "a modern drink"). Finally, inspiration and surprise drove attitudes linked to beverage brands.

Understanding Attitudes to Change to

Healthier Hydration Habits

\section{Attitude Profiles}

Using the Bayesian network analysis, 5 attitudes profiles appeared (Table 1). The notion of pleasure was found in 2 profiles: "mood and pleasure" and "pleasure and energy," representing almost half of the respondents (43\%). Self-image was particularly important for the "self-image and body image" profile and related to controlling food and drink intake and potential physical and health benefits. The "sharing and restoring" profile showed a dichotomy between moments to share beverages and other moments to drink individually to have a break and restore energy. The final profile, "health and success," was mostly defined by showing one's success, making again the link between health and self-image.

\section{Discussion}

The present study described the attitudes in life and toward drinking of adult Mexican HS-LWD, with the aim to identify potential drivers of behavior that could be used to promote healthier drinking habits. Attitudes in life and reasons to drink were found to be the entry points for understanding HS-LWD' attitudes toward drinking beverages. The relationship between the reasons to drink beverages and the attitudes in life was mediated by the reasons to drink linked to moments, suggesting that drinking behaviors are closely related to more general attitudes in life.

Our results suggest that social aspects, such as sharing with friends and family and self-image, were important aspects of SSB consumption. Social aspects were also identified in previous studies, among Mexican adolescents and among children $[24,25]$. These results, together with the description of the socioecological model [12], endorse the idea that such social factors need to be considered when designing strategies for changing drinking behavior. Furthermore, our results suggest that sensations, pleasure, and health benefits are key aspects for drinking behaviors. Reasons to drink were linked to individual benefits such as "being focused," "clean my body," and "prevent dehydration." Therefore, promoting health benefits that are already associated with drinking seems relevant to encourage healthier drinking. Another strategy would be to communicate on the pleasure and sharing opportunities that healthier options can also provide.

The observed 5 attitude profiles suggest that HS-LWD, although having the same fluid intake pattern, are not similar in why they drink. This segmentation can help developing tailored strategies. Tailored interventions have 
Table 1. Segmentation of the HS-LWD in 5 attitudes profiles

\begin{tabular}{|c|c|c|}
\hline Profile name & $\%$ & Most important items defining each profile \\
\hline Mood and pleasure & 26 & $\begin{array}{l}\text { Not stressed/not sad/not distant/not indifferent/not boring/not quiet } \\
\text { Drinking is a pleasure/physiological need/share } \\
\text { Drinking water is not impacting health } \\
\text { Prevent bad mood/stop boredom } \\
\text { No priority for (trust/uses no suspect ingredient)/drinking is not a constraint } \\
\text { Easily sharable/ready to use/intense taste/boost energy }\end{array}$ \\
\hline $\begin{array}{l}\text { Self-image and body } \\
\text { image }\end{array}$ & 26 & $\begin{array}{l}\text { Share and enjoyment are not a priority } \\
\text { Diet is too rich in sugar/concerned by image-physical condition (priorities) } \\
\text { Most of the time, I control/reduce my daily consumption of food and drinks } \\
\text { Indifferent/boring/quiet } \\
\text { Make me reconnect } \\
\text { Help digestion } \\
\text { Energize/activate my body } \\
\text { Enhance metabolism/health/skin care } \\
\text { A ready-to-use drink/a drink which gives me prestige }\end{array}$ \\
\hline Sharing and restoring & 21 & $\begin{array}{l}\text { Friends are member of family } \\
\text { Show my success is important for me } \\
\text { Life is difficult and you always need money to live properly } \\
\text { Restore energy } \\
\text { Make a break } \\
\text { Feel my diet is too rich in sugar } \\
\text { Not stressed/not boring/not distant } \\
\text { Drinking is a pleasure/physiological need } \\
\text { Recommend/talk about (trendsetters) }\end{array}$ \\
\hline Pleasure and energy & 17 & $\begin{array}{l}\text { Drinking is a pleasure } \\
\text { Energize/clear my mind/activate my body } \\
\text { Stay alert } \\
\text { Give me energy } \\
\text { Offer diversity of taste and/or sensation } \\
\text { A drink for the pleasure of taste } \\
\text { A natural drink } \\
\text { Home-made drink }\end{array}$ \\
\hline Health and success & 10 & $\begin{array}{l}\text { Show my success is important for me } \\
\text { Most of the time, I control/reduce my daily consumption of food and drinks } \\
\text { Distant/sad/reliable/protective/active } \\
\text { Drinking water is not a constraint } \\
\text { Make me reconnect/clear my body/health care } \\
\text { A healthy drink } \\
\text { A ready-to-use drink } \\
\text { Being on the go/practicing sport/having a me-moment } \\
\text { Boring/distant/quiet }\end{array}$ \\
\hline
\end{tabular}

HS-LWD, high sugar-low water drinker.

previously been used with positive effects on fluid intake of Mexican children [26]. The largest proportion of HSLWD participants fell under 2 profiles: "mood and pleasure" and "self-image and body image." A tailored strategy could highlight the recognition of the physiological need to drink water, as an alternative when one feels that diet is too rich in sugar, to energize, prevent dehydration, and support health. As the "self-image and body image" and the "health and success" profiles care about people's perception of themselves, another opportunity is to pro- 
mote self-image benefits of water or other healthier drinks. This requires working on the image of the drink to make it more socially desirable, such as making it considered as a modern drink. Finally, as getting sensations and pleasure appear as core elements for 2 profiles ("mood and pleasure" and "pleasure and energy"), another opportunity is to develop and promote healthier alternatives that provide particularly pleasant tastes and sensations.

Some limitations should be noted. First, the fluid consumption questionnaire was self-declared, which is inherent to this type of studies but generally leads to overestimations. We partly addressed this by excluding extremely high fluid intakes. Another limit is that we did not control recruitment for socio-economic status. In future research, it would be interesting to investigate sociodemographic aspects. Finally, we lack the ability to compare the results with the general public as we focused on HS-LWD specifically. Yet, HS-LWD represent $37 \%$ of the Mexican population (unpublished data, Liq. In $^{7}$ survey [10]), which is a sizeable portion. Our study also has several strengths, including the large sample size which reduces the results margin of error. Furthermore, the questionnaire, assessing the major HS-LWD attitudes based on a previous qualitative study, and the Bayesian network analysis, allowed us to articulate the various sets of questions related to attitudes and find dependencies between them.

\section{Conclusion}

This study provides important insights concerning HS-LWD attitudes, constituting a first step in understanding the attitudes and behavior of this group. Future research is needed to investigate the recommendations stemming from this research in (tailored) intervention trials to modify drinking habits towards healthier choices.

\section{Statement of Ethics}

Ethical approval by a human research committee was not required since the study was a consumer insight/market study. The research was conducted ethically in accordance with the ICC/ESOMAR International Code on Market, Opinion and Social Research and Data Analytics, which sets out global standards for self-regulation for researchers and data analysts for carrying out market research. All subjects gave their written informed consent. The study protocol was approved by an internal steering committee overseeing the quality of all studies from the research group.

\section{Conflict of Interest Statement}

J.M. served as a consultant to Danone Research. A.A.C.V., I.S., and Q.D. are full time employee of Danone Research. I.G. is a former employee of Danone Research. H.M. received travel expenses and registration fees from Danone Research to attend the 2019 Hydration for Health Scientific Conference.

\section{References}

1 Chen L, Appel LJ, Loria C, Lin PH, Champagne CM, Elmer PJ, et al. Reduction in consumption of sugar-sweetened beverages is associated with weight loss: the PREMIER trial. Am J Clin Nutr. 2009;89(5):1299-306.

2 Tate DF, Turner-McGrievy G, Lyons E, Stevens J, Erickson K, Polzien K, et al. Replacing caloric beverages with water or diet beverages for weight loss in adults: main results of the choose healthy options consciously everyday (CHOICE) randomized clinical trial. Am J Clin Nutr. 2012 Mar;95(3):555-63.

3 Imamura F, O'Connor L, Ye Z, Mursu J, Hayashino Y, Bhupathiraju SN, et al. Consumption of sugar sweetened beverages, artificially sweetened beverages, and fruit juice and incidence of type 2 diabetes: systematic review, meta-analysis, and estimation of population attributable fraction. BMJ. 2015;351: h3576.

4 Malik VS, Popkin BM, Bray GA, Després JP, Willett WC, Hu FB. Sugar-sweetened beverages and risk of metabolic syndrome and type 2 diabetes: a meta-analysis. Diabetes Care. 2010;33(11):2477-83.
5 Strippoli GF, Craig JC, Rochtchina E, Flood VM, Wang JJ, Mitchell P. Fluid and nutrient intake and risk of chronic kidney disease. Nephrology. 2011;16(3):326-34.

6 Perrier ET, Armstrong LE, Bottin JH, Clark WF, Dolci A, Guelinckx I, et al. Hydration for health hypothesis: a narrative review of supporting evidence. Eur J Nutr. 2020 Jul 6.

7 World Health Organization. Guideline: sugars intake for adults and children. [cited 2020 Feb 19]. Available from: http://apps.who.int/ iris/bitstream/handle/10665/149782/ 9789241549028_eng.pdf? sequence $=1$.

8 Johnson EC, Péronnet F, Jansen LT, CapitanJiménez C, Adams JD, Guelinckx I, et al. Validation testing demonstrates efficacy of a 7-day fluid record to estimate daily water intake in adult men and women when compared with total body water turnover measurement. J Nutr. 2017;147(10):2001-7.

9 Sánchez-Pimienta TG, Batis C, Lutter CK, Rivera JA. Sugar-sweetened beverages are the main sources of added sugar intake in the mexican population. J Nutr. 2016 Sep;146(9): 1888S-96S.
10 Martinez H, Morin C, Gandy J, Carmuega E, Arredondo JL, Pimentel C, et al. Fluid intake of Latin American adults: results of four 2016 Liq.In7 national cross-sectional surveys. Eur J Nutr. 2018;57(S3):65-75.

11 DiBonaventura MD, Meincke H, Le Lay A, Fournier J, Bakker E, Ehrenreich A. Obesity in Mexico: prevalence, comorbidities, associations with patient outcomes, and treatment experiences. Diabetes Metab Syndr Obes. 2018 Dec;11:1-10.

12 Meza R, Barrientos-Gutierrez T, Rojas-Martinez R, Reynoso-Noverón N, Palacio-Mejia LS, Lazcano-Ponce E, et al. Burden of type 2 diabetes in Mexico: past, current and future prevalence and incidence rates. Prev Med. 2015;81:445-50.

13 Braverman-Bronstein A, Camacho-GarcíaFormentí D, Zepeda-Tello R, Cudhea F, Singh GM, Mozaffarian D, et al. Mortality attributable to sugar sweetened beverages consumption in Mexico: an update. Int J Obes. 2020 Jun;44(6):1341-9.
Understanding Attitudes to Change to Healthier Hydration Habits
Ann Nutr Metab 2020;76(suppl 1):43-52 DOI: $10.1159 / 000515023$ 
14 Park S, Thompson FE, McGuire LC, Pan L, Galuska DA, Blanck HM. Sociodemographic and behavioral factors associated with added sugars intake among US adults. J Acad Nutr Diet. 2016 Oct;116(10):1589-98.

15 Dahlgren G, Whitehead M. Policies and strategies to promote social equity in health. Stockholm: Institute for future studies; 1991. Vol. 27.1; p. 4-41.

16 Fishbein M, Ajzen I. Belief, attitude, intention, and behavior: an introduction to theory and research. Reading, MA: Addison-Wesley; 1975.

17 Eagly AH, Chaiken S. The psychology of attitudes. Fort Worth, TX: Harcourt, Brace \& Janovith; 1993. Vol. 79; p. 15.
18 Zoellner J, Estabrooks PA, Davy BM, Chen YC, You W. Exploring the theory of planned behavior to explain sugar-sweetened beverage consumption. J Nutr Educ Behav. 2012; 44(2):172-7.

19 Imoisili OE, Park S, Lundeen EA, Yaroch AL Blanck HM. Daily adolescent sugar-sweetened beverage intake is associated with select adolescent, not parent, attitudes about limiting sugary drink and junk food intake. Am J Health Promot. 2020 Jan;34(1):76-82.

20 Beaulieu D, Vézina-Im LA, Turcotte S, Guillaumie L, Boucher D, Douville F, et al. Correlates of sugar-sweetened beverages consumption among adolescents. Public Health Nutr. 2020 Aug;23(12):2145-54.

21 Asociación Mexicana de Agencias de Investigación de Mercado y Opinión Pùblica. Niveles Socioeconómicos. [cited Nov 18]. Available from: http://nse.amai.org/.
22 Carlin BP, Louis TA. Bayes and empirical Bayes methods for data analysis: Chapman and Hall/CRC; 2010.

23 Conrady S, Jouffe L. Introduction to bayesian networks \& BayesiaLab. 2013 Sep;3:201, 3.

24 Ortega-Avila AG, Papadaki A, Jago R. The role of the home environment in sugar-sweetened beverage intake among northern Mexican adolescents: a qualitative study. J Public Health. 2018 Nov:1-11.

25 Duh-Leong C, Braganza S. Social networks and sugar-sweetened beverage consumption in a pediatric Urban academic practice. Behav Med. 2020 Jan-Mar;46(1):1-8.

26 Carriedo Á, Bonvecchio A, López N, Morales $\mathrm{M}$, Mena C, Théodore FL, et al. Use of social marketing to increase water consumption among school-age children in Mexico City. Salud Publica Mex. 2013;55(Suppl 3):388-96. 